\title{
Suramin induced ceramide accumulation leads to apoptotic cell death in dorsal root ganglion neurons
}

\author{
Jagjit S. Gill ${ }^{1,2}$ and Anthony J. Windebank ${ }^{1}$ \\ ${ }^{1}$ Molecular Neuroscience Program and Mayo Cancer Center, Mayo Clinic and \\ Mayo Foundation, 1501 Guggenheim Building, 200 First Street SW, \\ Rochester, Maine 55905, USA \\ 2 corresponding author: Jagjit S. Gill, Ph.D., Mayo Clinic and Mayo Foundation, \\ Department of Neurology, 1521 Guggenheim Building, 200 First Street SW, \\ Rochester, Maine 55905, USA. Phone: 507-284-1781; Fax: 507-284-3383; \\ E-mail: gill.jagjit@mayo.edu
}

Received 10.11.97; revised 3.4.98; accepted 8.5.98 Edited by S. Korsmeyer

\begin{abstract}
Suramin is an experimental antineoplastic agent that is currently being tested in clinical trials for a number of human cancers. In previous clinical trials, it has been noted that a significant percentage of patients treated with suramin develop a peripheral neuropathy. Both the cytotoxic (chemotherapeutic) and neurotoxic mechanisms of action of this compound are unknown. Evidence presented in this study suggests that both effects may be due to extensive disruption in glycolipid transport and/or metabolism. Suramin treated dorsal root ganglion cultures revealed an accumulation of the $\mathrm{GM}_{1}$ ganglioside and ceramide. Exposure of cultures to suramin, a cell permeable ceramide analog, or sphingomyelinase lead to apoptotic cell death demonstrated by electron microscopy, bis-benzimide staining and DNA laddering on gel electrophoresis. Furthermore, a significant increase in intracellular ceramide preceded cell death in suramin treated neurons. We propose that suramin induced ceramide accumulation within neurons leads to apoptotic cell death.
\end{abstract}

Keywords: apoptosis; ceramide; peripheral neuropathy; chemotherapy; dorsal root ganglion

Abbreviations: DRG, dorsal root ganglion; LIB, lamellar inclusion bodies; NGF, nerve growth factor; TUNEL, terminal deoxynucleotidyl transferase mediated dUTP nick end labeling; MS, mass spectrometry

\section{Introduction}

Suramin is a polysulfonated naphthylurea developed subsequent to observations on the trypanocidal activity of the azo dyes trypan red and trypan blue (Hawking, 1978). It has recently been used as an experimental chemotherapeutic agent for the treatment of a number of human malignancies (Broder et al, 1985; Stein et al, 1988; La Rocca et al, 1990a; Pollak and Richard, 1990; LaRocca et al, 1991). Initial clinical trials revealed major toxicities.
In one study, $80 \%$ of patients experienced symptoms of peripheral neuropathy (LaRocca et al, 1989). A subsequent study reported that in patients with disseminated cancer given suramin; four developed a sensorimotor neuropathy with electrophysiologic and histologic features of axonal degeneration and segmental demyelination (LaRocca et al, 1990b). Neuropathy was most likely to occur in those patients with peak plasma suramin levels above $350 \mu \mathrm{g} / \mathrm{ml}$, implying a dose response effect. Thus, severe peripheral neuropathy is a major dose limiting effect of suramin.

In spite of major toxicities, suramin has been documented to have significant in vitro and in vivo activity against a variety of solid tumor cell lines at drug concentrations that are clinically achievable (Betscholtz et al, 1986; Coffey et al, 1987; Kim et al, 1991; Gansler et al, 1992). For this reason, there continues to be considerable clinical interest in this drug. However, the mechanism of anti-tumor activity and neurotoxicity of the drug remain unknown. Most reports on suramin describe an inhibitory effect on growth factor receptor binding as its cytotoxic mechanism of action (Hosang, 1985; Coffey et al, 1987; Sjölund and Thyberg, 1989; Pollack and Richard, 1990). Other studies have reported a stimulatory effect by suramin on growth factor receptors (Mahoney et al, 1990; Cardinali et al, 1992; Sartor et al, 1992; Tsutsumi et al, 1993; Tsutsumi et al, 1994). This suggests a pleiotropic effect of suramin on growth factor receptors. Previous studies from our laboratory indicate that suramin's interaction with the high affinity nerve growth factor (NGF) receptor (TrkA) probably does not play a role in drug induced neurotoxicity (Gill et al, 1996; Gill and Windebank, 1998).

Other studies have suggested that suramin treatment (in vitro and in vivo) leads to the accumulation of lamellar inclusion bodies (LIB) that morphologically resemble those observed in lysosomal storage diseases (Buys et al, 1978; Rees, 1978; Constantopoulos et al, 1981; Rees et al, 1982; Akanji, 1988). In dorsal root ganglion (DRG) neurons in vitro and in vivo, characteristic LIB begin to form within hours of suramin exposure; dying cells are full of LIB (Gill et al, 1995). There is a concomitant rise in intracellular $\mathrm{GM}_{1}$ ganglioside levels localized to LIB.

A key element in this study is investigating ways to separate the neurotoxic effects of chemotherapeutic agents from their cytotoxic efficacy. In particular, we wish to understand why an anti-cancer drug designed to kill rapidly dividing cells would injure the DRG, composed of postmitotic primary afferent sensory neurons and post-mitotic Schwann cells involved in myelination. A potential link between rapidly dividing cancer cells and post-mitotic DRG neurons is their relatively high rates of glycosphingolipid (ganglioside) synthesis.

From our work and others, it is clear that suramin treatment results in glycolipid accumulation. The focus of this study was to characterize the mechanism of neuronal 
(DRG) cell injury and cell death associated with sphingolipid defects. Such studies propose an alternative cytocidal mechanism mediated by suramin, namely the accumulation of ceramide, and its role in programmed/apoptotic cell death. This work contributes to established findings describing the role of sphingolipids in signal transduction and cell regulation as a mechanism of growth suppression and cell death (Hannun and Linardic, 1993; Obeid et al, 1993; Hannun and Obeid, 1995; Brugg et al, 1996).

\section{Results}

Cell viability studies revealed a dose dependent reduction in neuron survival in suramin treated cultures (Figure 1). Cultures exposed to 300 and $600 \mu \mathrm{M}$ suramin revealed a significant reduction in neuron viability after $48 \mathrm{~h}$ of treatment $(81 \% \pm 4.1$ and $75 \% \pm 3.9$ cell viability, respectively). Neuronal loss continued with length of suramin exposure: $40 \%( \pm 4.9)$ and $16 \%( \pm 5.2)$ cell viability after 10 days exposure to 300 and $600 \mu \mathrm{M}$ suramin, respectively. In subsequent studies, DRG cultures were exposed to $300 \mu \mathrm{M}$ suramin for $12 \mathrm{~h}$ to 4 days. This concentration of suramin is comparable to doses of drug reported in clinical and animal studies to precipitate a peripheral sensory neuropathy.

\section{Lysosomal accumulation of $\mathrm{GM}_{1}$ ganglioside}

Electron microscopic studies revealed dying neurons full of LIB (Figure 2). Suramin treated cultures revealed apoptotic neurons with characteristic nuclear fragmentation and intact nuclear and cytoplasmic membranes. DRG cultures labeled with Texas Red-dextran displayed an abundance of lysosomes/inclusion bodies within the cytoplasm of suramin treated DRG neurons (Figure 3). Limited fluorescent lysosomal profiles were seen in untreated cultures. Suramin treated DRG cultures accumulated monosialoganglioside

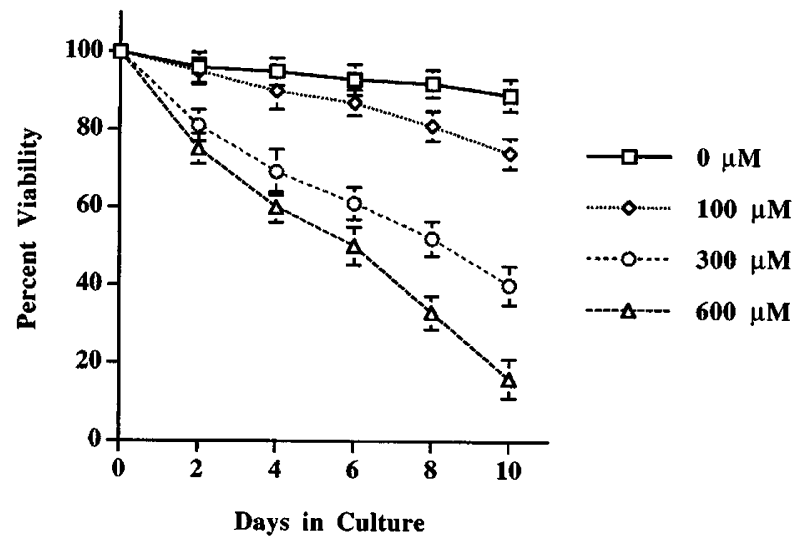

Figure 1 Neuron survival was studied using phase contrast microscopy and grid counting. The number of viable neurons was determined after exposure to 100,300 , and $600 \mu \mathrm{M}$ suramin. Neuron-enriched DRG cultures exposed to either 300 or $600 \mu \mathrm{M}$ suramin revealed a significant reduction in cell viability after 2 days in culture ( $P<0.01$ Student's $t$-test). DRG cultures revealed a dose dependent reduction in neuronal viability with continued exposure to suramin. Cultures exposed to subtoxic concentrations of suramin $(100 \mu \mathrm{M})$ only revealed a significant reduction in neuron viability after 8 days in culture
$\mathrm{GM}_{1}$ as detected by cholera toxin- $\beta$ subunit labeling (Figure $4 \mathrm{~A})$. Positive and punctate staining was seen within the cytoplasm and plasma membrane. $\mathrm{GM}_{1}$ labeling was not observed within the nucleus. The punctate ganglioside staining revealed a cellular distribution similar to that observed in cultures labeled with Texas Red-dextran. Cultures exposed to suramin and the glucosylceramide synthase inhibitor PDMP revealed reduced levels of $\mathrm{GM}_{1}$ ganglioside via cholera toxin- $\beta$ staining. Inhibition of ganglioside biosynthesis with exposure of cultures to PDMP did not prevent suramin induced cell death (Figure 4B). DRG cultures
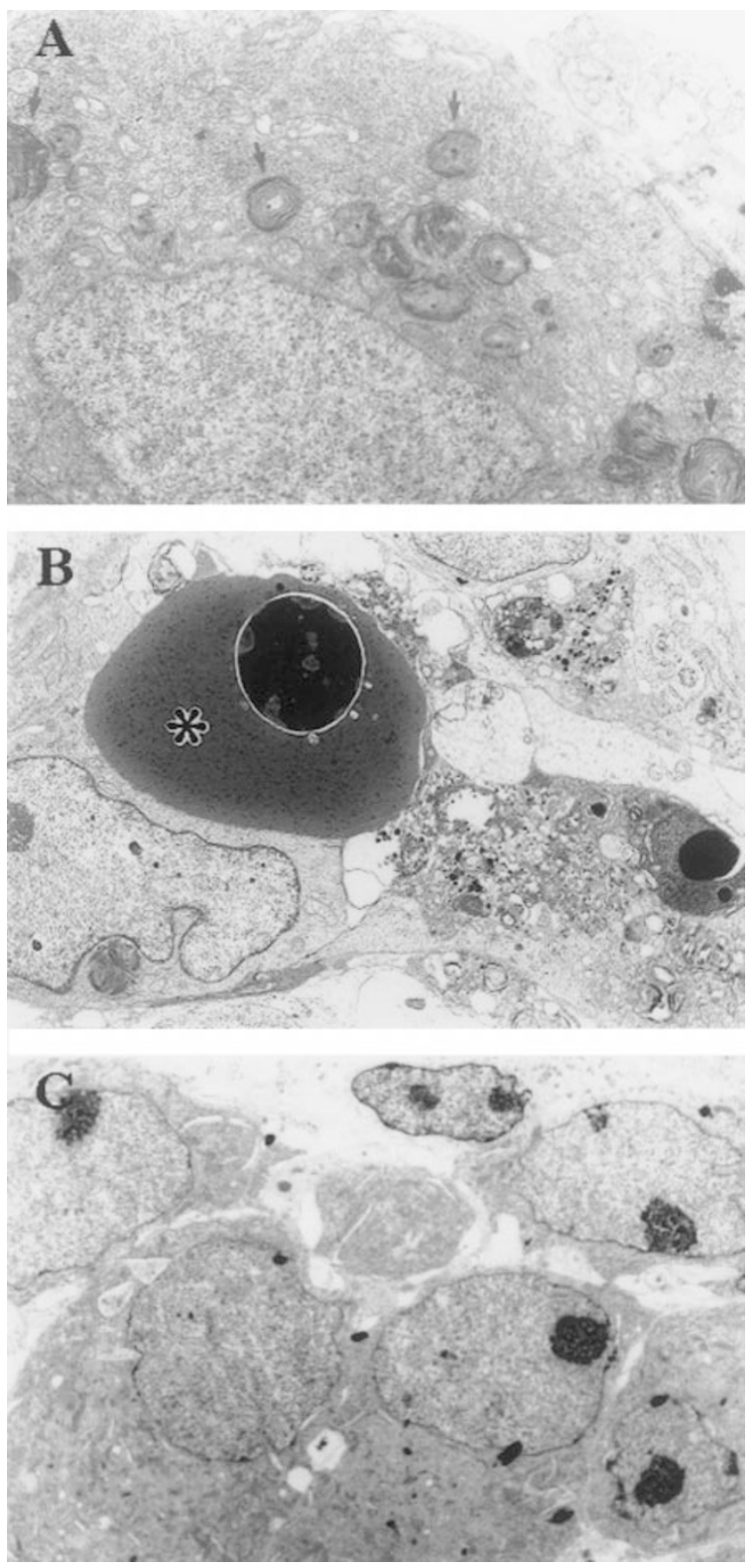

Figure 2 Electron micrographs from rat DRG cultures treated with $300 \mu \mathrm{M}$ suramin for $24 \mathrm{~h}$ revealed the accumulation of LIB (A; arrow, mag $\times 4800$ ). Suramin treatment for $48 \mathrm{~h}(B ; \mathrm{mag} \times 2800)$ revealed changes consistent with apoptosis in a neuron (*) displaying condensed chromatin and intact cell and nuclear membranes. Control cultures $(\mathbf{C} ; \mathrm{mag} \times 2100)$ did not display LIB and apoptotic figures were rarely seen 

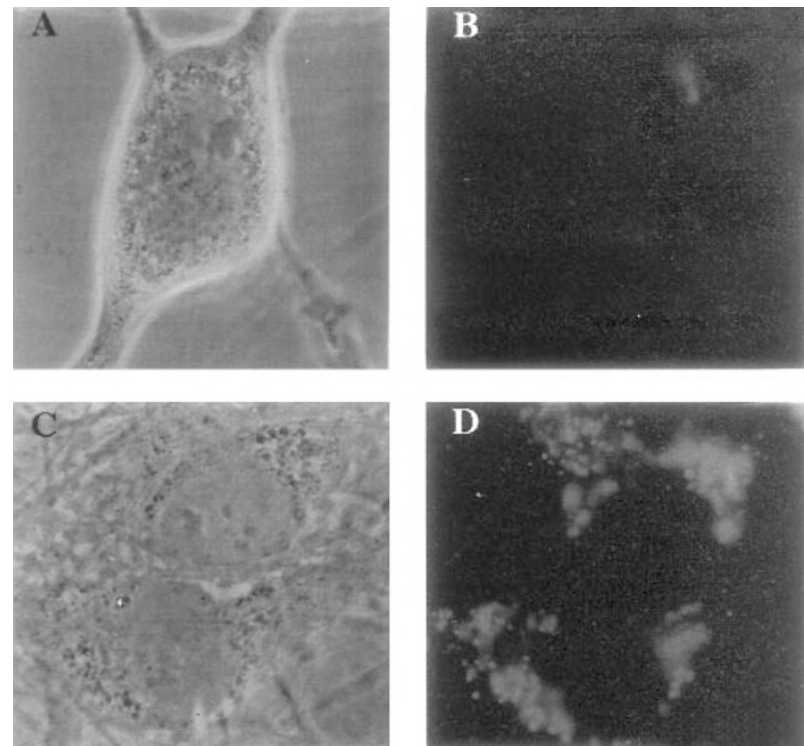

Figure 3 DRG neuronal cultures went untreated $(\mathbf{A}, \mathbf{B})$ or exposed to $300 \mu \mathrm{M}$ suramin $(\mathbf{C}, \mathbf{D})$ for $48 \mathrm{~h}$. Under phase contrast microscopy, suramin treated neurons (C) have an abundance of inclusion bodies which are detected as Iysosomal profiles with Texas Red-dextran under fluorescence microscopy (D). Untreated neurons did not reveal any significant LIB under phase (A) or fluorescence micrsocopy $(B ; \operatorname{mag} \times 400)$

exposed to $300 \mu \mathrm{M}$ suramin, with or without $10 \mu \mathrm{M}$ PDMP, revealed internucleosomal fragmentation by gel electrophoresis indicative of apoptotic cell death.

\section{Suramin induced apoptosis in DRG neurons}

Apoptotic changes were observed in suramin treated DRG cultures by electron microscopy (Figure 2) and bis-benzimide stain (Figure 5). Under fluorescence microscopy, neuronal nuclear and cellular condensation and fragmentation were observed by 36 to $48 \mathrm{~h}$ of suramin treatment (Figure 5). Phase contrast images revealed intact cellular membranes. Condensed and fragmented nuclei observed with bis-benzimide stain were only observed in Schwann cells and fibroblasts of DRG cultures exposed to suramin for longer than $72 \mathrm{~h}$. Nuclear changes characteristic of apoptosis were also observed by the terminal deoxynucleotidyl transferase mediated dUTP nick end labeling (TUNEL) technique (data not shown) (Pittman et al, 1993; Piqueras et al, 1996). Enriched DRG neuronal cultures were established and used to study the integrity of genomic DNA after suramin treatment (Figures 4 and 6). DNA laddering suggestive of internucleosomal strand digestion was observed with suramin treatment (300 $\mu \mathrm{M}$ for $48 \mathrm{~h}$ ), correlating with morphological evidence indicative of apoptosis. In all of the above methods used to study apoptotic death, suramin $(300 \mu \mathrm{M})$ induced neuronal apoptosis was observed by $36-48 \mathrm{~h}$ treatment in vitro.

\section{Ceramide mediated apoptosis in DRG neurons}

DRG cultures exposed to $10 \mu \mathrm{M}$ of the short chain ceramide analog $\mathrm{C}_{2}$-ceramide and $300 \mathrm{mU} / \mathrm{ml}$ sphingomyelinase were also stained with bis-benzimide and TUNEL. Bis-benzimide
A
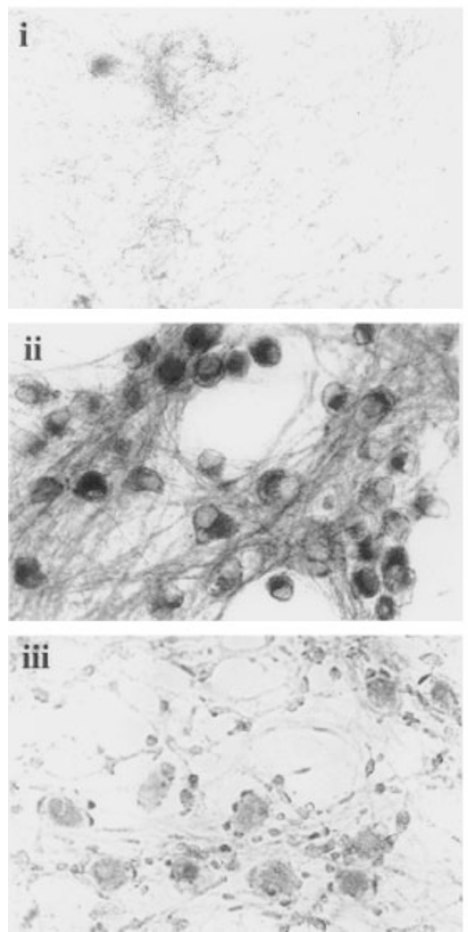

B

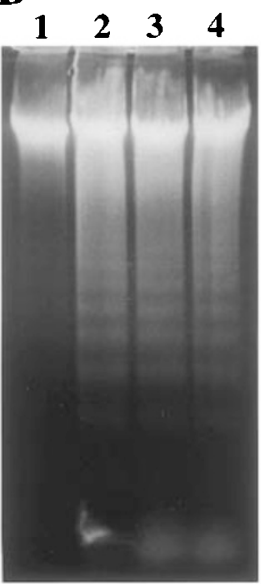

Figure 4 (A) DRG cultures were treated with $300 \mu \mathrm{M}$ suramin for $48 \mathrm{~h}$, fixed, and immunostained with cholera toxin- $\beta$ subunit, a specific marker for $\mathrm{GM}_{1}$ ganglioside. Positive staining was observed with the brown chromagen diaminobenzidine. Suramin treated cultures (ii) revealed an accumulation of $\mathrm{GM}_{1}$ ganglioside within the cytoplasm of neurons and along neuroitic processes as compared to untreated cultures (i). The punctate cholera toxin- $\beta$ staining of $\mathrm{GM}_{1}$ ganglioside within the cytoplasm of neurons codistributed with LIB/lysosomal staining via Texas Red-dextran labeling in Figure 3. Cultures exposed to suramin and $10 \mu \mathrm{M}$ of d,l-threo-PDMP (iii); (an inhibitor of glucosyl ceramide synthase) reduced the level of $\mathrm{GM}_{1}$ ganglioside staining. Neuronal cultures exposed to suramin and the inactive diastereomer d,l-erythro-PDMP revealed $\mathrm{GM}_{1}$ ganglioside accumulation comparable to cultures exposed to suramin alone (data not shown). (B) Neuron-enriched DRG cultures were exposed to $300 \mu \mathrm{M}$ suramin alone (lane 2) or with the addition of $10 \mathrm{~d} \mu \mathrm{M} d$,I, threo-PDMP (lane 3) or $10 \mu \mathrm{M}$ d,l-erythro-PDMP (lane 4) for $48 \mathrm{~h}$. Internucleosomal fragmentation by gel electrophoresis, characteristic of apoptotic cell death, was observed in cultures exposed to suramin alone as well as those exposed to suramin and PDMP. Untreated/control cultures (lane 1) revealed intact genomic DNA

staining revealed apoptotic profiles in DRG neurons exposed to sphingomyelinase and $\mathrm{C}_{2}$-ceramide similar to those in suramin treated cultures (Figure 5). Apoptotic cells, as determined by nuclear condensation and blebbing were first observed at $24 \mathrm{~h}$ exposure to both $\mathrm{C}_{2}$-ceramide and sphingomyelinase. TUNEL analysis also revealed nuclear fragmentation in neurons exposed to $\mathrm{C}_{2}$-ceramide (data not shown). As a positive control for neuronal apoptosis, DRG neurons were cultured in the absence of NGF, which revealed apoptotic profiles by $12-24 \mathrm{~h}$. This model of neuronal apoptosis has been described previously (Deckwerth and Johnson, 1993; Edwards and Tolkovsky, 1994).

Enriched DRG neuronal cultures treated with $\mathrm{C}_{2}$ ceramide also revealed DNA laddering by gel electrophor- 

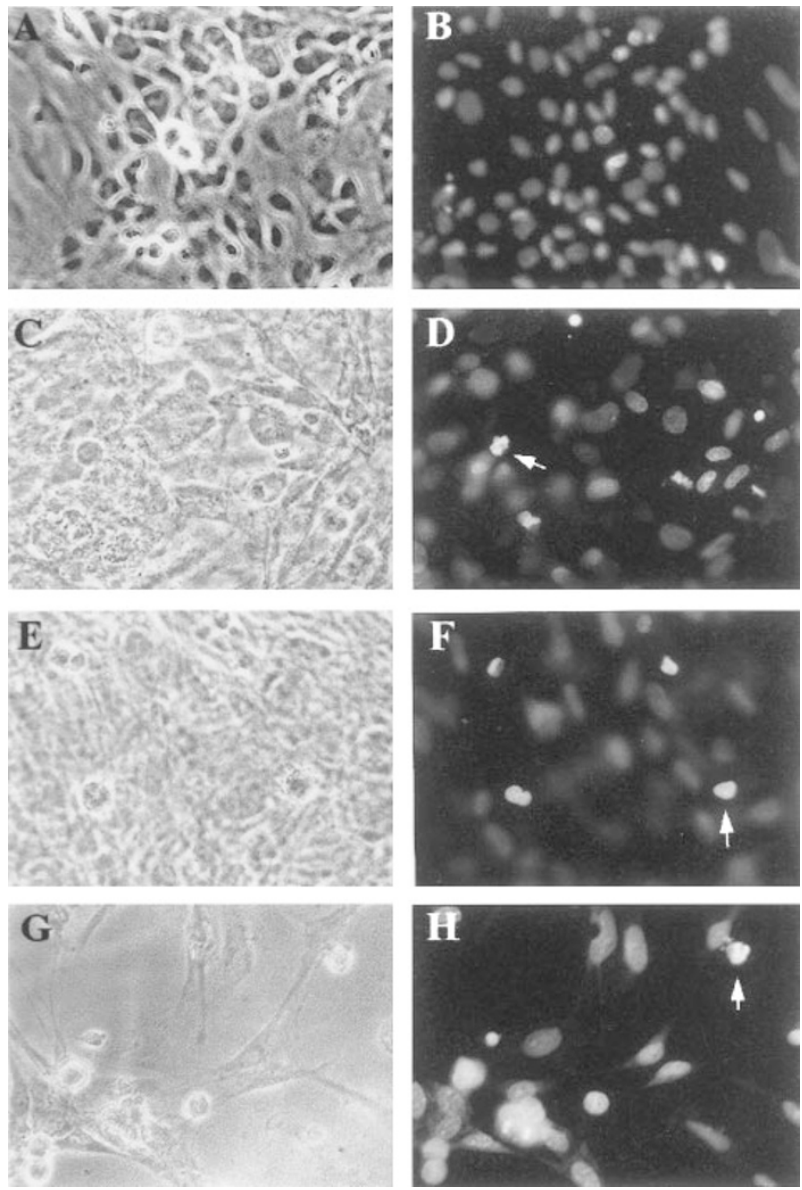

Figure 5 DRG cultures were exposed to $300 \mu \mathrm{M}$ suramin (C,D; $48 \mathrm{~h}$ ), $10 \mu \mathrm{M}$ $\mathrm{C}_{2}$-ceramide $(\mathbf{E}, \mathbf{F} ; 24 \mathrm{~h}$ ) or $300 \mathrm{mU} / \mathrm{ml}$ sphingomyelinase $(\mathbf{G}, \mathbf{H} ; 24 \mathrm{~h})$, fixed and stained with bis-benzimide (Hoechst 33258). Phase (A,C,E,G) and fluorescence $(\mathbf{B}, \mathbf{D}, \mathbf{F}, \mathbf{H})$ microscopic images of representative areas were obtained (mag $\times 100)$. Apoptotic cells (arrow) identified with condensed and fragmented nuclei with bis-benzimide stain were observed in cultures treated with suramin, $\mathrm{C}_{2}$-ceramide, and sphingomyelinase. Similar apoptotic bodies were not observed in untreated cultures $(\mathbf{A}, \mathbf{B})$

esis (Figure 6). Similar profiles of internucleosomal fragmentation manifested as DNA laddering were observed in cultures treated with suramin and those cultured in the absence of NGF. Untreated cultures and those exposed to $10 \mu \mathrm{M}$ dihydroceramide for $48 \mathrm{~h}$ did not reveal any DNA laddering.

\section{Ceramide measurement}

Enriched neuronal cultures were used to investigate changes in total intracellular ceramide levels induced by $300 \mu \mathrm{M}$ suramin exposure. Two independent means were used to quantitate changes in intracellular ceramide: the diacyglycerol kinase assay and MS analysis. Accumulation of total intracellular ceramide was observed by the diacylglycerol kinase assay (Figure 7A). These studies revealed a 2.53 fold increase over untreated neuronal cultures of intracellular ceramide after $24 \mathrm{~h}$ of suramin $(300 \mu \mathrm{M})$ treatment and 5.73 fold increase in cultures exposed to drug for $48 \mathrm{~h}$. Electrospray ionization MS analysis was performed as

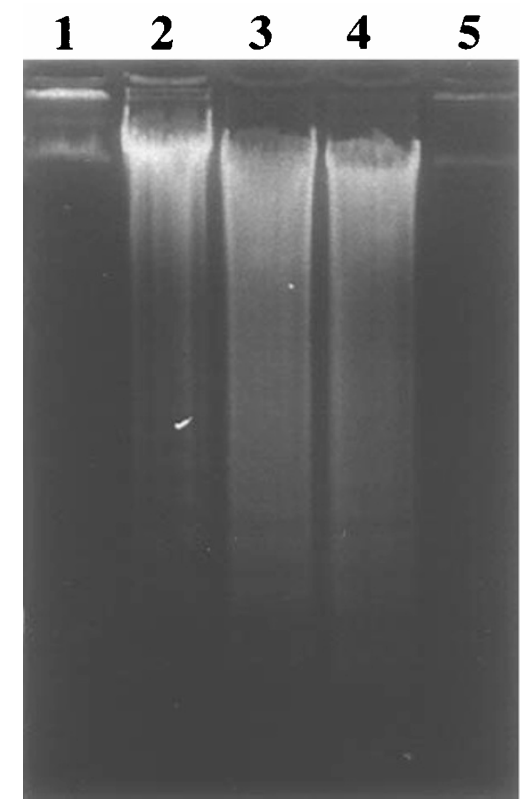

Figure 6 Neuron-enriched DRG cultures were exposed to NGF withdrawal (lane 2), $300 \mu \mathrm{M}$ suramin (lane 3), $10 \mu \mathrm{M} \mathrm{C}_{2}$-ceramide (lane 4), or $10 \mu \mathrm{M}$ dihydroceramide (lane 5) for $48 \mathrm{~h}$. Isolated DNA was separated on a $1.2 \%$ agarose gel and visualized by ethidium bromide. DNA laddering characteristic of apoptosis was observed in cultures exposed to suramin and $\mathrm{C}_{2}$-ceramide. NGF withdrawal was used as an established model of neuronal apoptosis and DNA laddering. Untreated cultures and those exposed to dihydroceramide (an inactive $\mathrm{C}_{2}$-ceramide analog) did not induce DNA laddering (lanes 1 and 5 , respectively)

described in a recent report (Figure 7B) (Watts et al, 1997). Total ceramide levels in neuron enriched DRG cultures increased significantly by $12 \mathrm{~h}$ exposure to 300 and $600 \mu \mathrm{M}$ suramin $(132 \% \pm 8.5$ and $144 \% \pm 11.0$ of control, respectively). Ceramide levels increased further after $24 \mathrm{~h}$ suramin treatment. Cultures exposed to subtoxic concentrations of suramin $(100 \mu \mathrm{M})$ did not product significant changes in ceramide levels as compared to untreated cultures.

\section{Discussion}

In the present study, sensory neurons exposed to the chemotherapeutic agent suramin displayed distinct structural and biochemical changes compatible with apoptotic cell death. Electron microscopic analysis of suramin treated DRG neurons revealed characteristic apoptotic changes; condensed cells, nuclear condensation and fragmentation, and intact cell and nuclear membranes. In vivo studies of suramin treated rats have revealed similar profiles of apoptotic cell death in DRG neurons (Russell and Windebank, 1993). Additional evidence of suramin induced apoptosis was revealed by bis-benzimide staining and internucleosomal fragmentation with gel electrophoresis. Evidence of necrotic swelling was observed in suramin treated cultures only at prolonged exposure times $(>72 \mathrm{~h})$. This is consistent with other reports of necrotic cell death following apoptotic injury (Wyllie et al, 1980; Wyllie, 1985). 
A

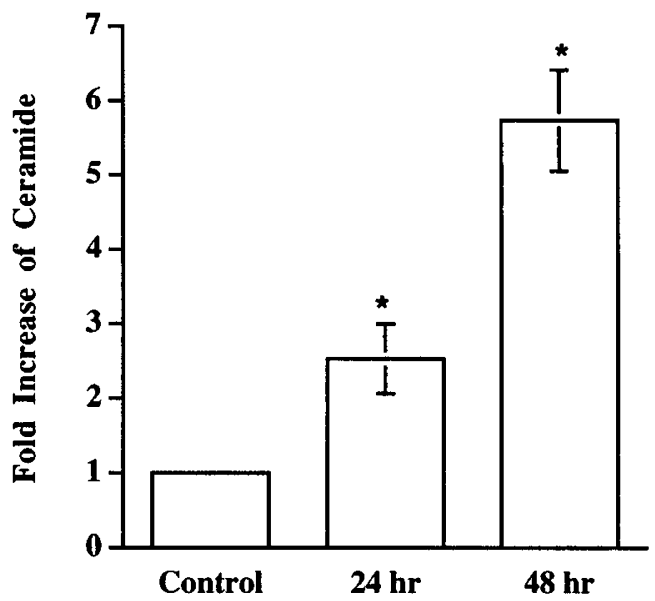

B

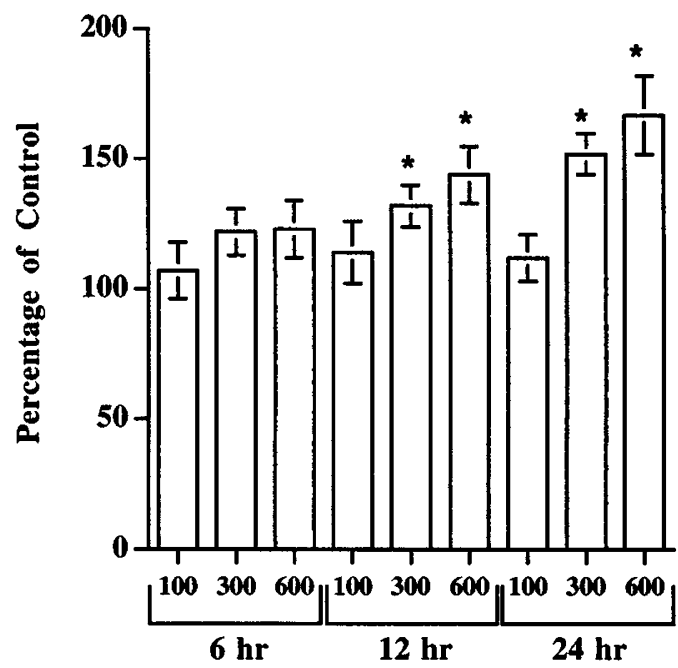

Figure 7 (A) Intracellular ceramide was measured by the diacylglycerol kinase assay from neuron-enriched DRG cultures. Densitometry revealed that $300 \mu \mathrm{M}$ suramin treatment resulted in a $2.53( \pm 0.47)$ and $5.74( \pm 0.68)$ fold increase in intracellular ceramide at 24 and $48 \mathrm{~h}$, respectively. Ceramide measurements were the mean of three experiments (error bars represent S.E.M.; *indicates a significant change as compared to untreated cultures, $P<0.01$ Student's $t$-test). (B) Cellular sphingosine-based ceramide levels in suramin treated neuron-enriched DRG cultures were also determined by MS analysis. Cultures were exposed to 100,300 or $600 \mu \mathrm{M}$ suramin for 6, 12 or $24 \mathrm{~h}$. Lipid extractions and MS analyses were performed as described in Materials and methods. Signal intensitities of all ceramide families (summation of peaks from 500 to $990 \mathrm{~m} / \mathrm{z}$ ) were normalized to signal intensity from internal C2:0 standard. Values plotted are relative signal intensities as percentage of control/untreated cultures. Cultures exposed to 300 and $600 \mu \mathrm{M}$ suramin revealed significant changes in total ceramide levels after 12 and $24 \mathrm{~h}$ exposure ( ${ }^{*}$ indicates a significant change as compared to untreated cultures, $P<0.01$ Student's $t$-test). MS analyses were the mean of three experiments (error bars represent S.E.M.)

The monosialoganglioside $\mathrm{GM}_{1}$ is the predominant glycosphingolipid in developing DRG neurons. The significance of drug induced $\mathrm{GM}_{1}$ ganglioside accumulation regarding suramin mediated neurotoxicity was clearly warranted. In our study, inhibition of endogenous ganglioside biosynthesis in suramin treated neuronal cultures reduced the levels of cholera toxin- $\beta$ staining of $\mathrm{GM}_{1}$ ganglioside but was not able to rescue the cells from drug induced apoptosis. While these findings suggested that ganglioside accumulation by itself is not sufficient to promote suramin induced neuronal damage, it allowed us to focus on the effects of glycosphingolipid precursor upregulation or accumulation (i.e. ceramide).

Light microscopic analysis by bis-benzimide staining and DNA laddering by gel electrophoresis also revealed apoptotic cell death of DRG neurons exposed to the short chain ceramide analog $\mathrm{C}_{2}$-ceramide or sphingomyelinase. The onset of ceramide induced apoptosis in DRG neurons was comparable to recent reports describing ceramide mediated programmed cell death in mesencephalic neurons and embryonic chick cerebral neurons (Brugg et al, 1996; Wiesner and Dawson, 1996). Nonspecific ceramide toxicity was excluded as the dihydroceramide analog of $\mathrm{C}_{2}$ ceramide, which differs only by the absence of 4-5 trans double bond in the sphingosine moiety, had no effect on DNA integrity as determined by gel electrophoresis (Figure 6). Similar results were observed in TUNEL studies (data not shown). This analog has previously been shown incapable of inducing apoptosis and internucleosomal
DNA digestion (Bielawska et al, 1993; Obeid et al, 1993). This result along with other findings presented here provide strong evidence that neurons exposed to suramin or agents that elevate intracellular ceramide levels (i.e. $\mathrm{C}_{2}$-ceramide or sphingomyelinase) initiate a pathway leading to programmed cell death.

The observed time course of ceramide mediated cell death in DRG neurons is compatible with the activation of a regulated program involving new gene transcription and/or protein synthesis. The longer period for suramin mediated changes in nuclear integrity would correspond to the time needed to accumulate ceramide levels via defects in glycolipid metabolism sufficient to initiate a ceramide mediated cell death pathway. Alternatively, NGF withdrawal revealed the earliest signs of apoptotic cell death, an event described in earlier reports (Deckwerth and Johnson, 1993; Edwards and Tolkovsky, 1994). Whether NGF withdrawal involves ceramide mediated cell death pathways has not been determined.

In this study, suramin induced accumulation of ceramide was measured by two independent assays. While a recent report challenges the reliability of ceramide measurement via the diacylglycerol kinase assay (Watts et al, 1997), similar ceramide levels were observed by both MS analysis and the diacylglycerol kinase assay in suramin treated neuronal cultures (Figure 7). Accumulation of ceramide was observed within $12 \mathrm{~h}$ of suramin treatment, consistent with recent reports describing ceramide changes sufficient to initiate a cell death pathway (Brugg et al, 1996; Wiesner 
and Dawson, 1996). In both assays, significant accumulation of ceramide was observed before any morphological changes conforming to apoptotic cell death. These findings suggest that suramin mediated ceramide accumulation precedes and possibly initiates a cell death pathway rather than being a nonspecific consequence of drug induced cell damage.

The developing neurons used in this study are rapidly growing and elaborating axonal membranes. It is logical that glycosphingolipid synthesis will be maximally upregulated and that degradation pathways may be relatively inactive. Based on our studies using the pharmacologic inhibitor of ganglioside biosynthesis (Figure 4), we postulate that the rapid appearance of LIB is due to suramin induced production of ceramide with subsequent synthesis into complex glycosphingolipids (i.e. gangliosides). Furthermore, suramin induced LIB accumulation could be potentiated by a defect in trafficking of synthesized gangliosides to their correct target (unpublished observations). The expanding pool of gangliosides, accumulating from upregulation of precursor synthesis (i.e. ceramide) collect in lysosomes.

Finally, the role of ceramide in suramin mediated neuronal death presented in this study correlates with the drug's effect on cancer cells. A recent report described a similar mechanism of ceramide mediated cell death in a number of human cancer cell lines exposed to suramin (Gill and Windebank, 1997). It is proposed that suramin's cytotoxic and neurotoxic mechanisms of action are similar. Studies are underway to investigate the rate of glycolipid metabolism in the cancer cells in comparison to neurons.

\section{Materials and Methods}

\section{Tissue culture}

Embryonic day 15 rat pups were removed from the uterus under pentobarbital anesthesia. Pups were removed from the amniotic sac and held in Leibowitz L15 medium (GIBCO, Gaithersburg, MD), at $4^{\circ} \mathrm{C}$ during dissection. Each pup was decapitated and then DRG removed by microdissection. DRG were pooled and incubated with $0.25 \%$ trypsin in Hanks Balanced Salt Solution (GIBCO) for 30 min at $37^{\circ} \mathrm{C}$. DRG were sedimented at 1000 r.p.m. for 5 min, supernatant removed, dissociated further with a small bore pipette, and resuspended in Eagle's Minimal Essential Medium (GIBCO) supplemented with 15\% calf bovine serum (Hyclone, Logan UT) $10 \mathrm{ng} / \mathrm{ml} 2.5 \mathrm{~S} N \mathrm{NGF}$ (Boehringer Mannheim, Indianapolis, IN), 0.6\% glucose, $1.4 \mathrm{mM} \mathrm{L-}$ glutamine, and $50 \mu \mathrm{g} / \mathrm{ml}$ ascorbic acid. Dissociated DRG were plated onto ACLAR (American Chemical, Pleasant Gap, PA) dishes coated with ammoniated and air-dried rat tail collagen (Bornstein, 1958). Cells were grown overnight before the addition of antimetabolites $(10 \mu \mathrm{M}$ fluorodeoxyuridine; Sigma Chemical Co., St. Louis, MO) for 4 days. This yielded a predominantly neuronal culture.

Suramin (Mobay Chemical Corp., New York, NY) was constituted in standard medium and exposed to cultures for $12 \mathrm{~h}$ to 4 days. Cultures were also exposed to $5-10 \mu \mathrm{M}$ of the short chain ceramide analog $\mathrm{C}_{2}$-ceramide (Matreya Inc., Pleasant Gap, PA) as well as 5$10 \mu \mathrm{M}$ of the structurally related lipid analog dihydroceramide (Matreya) which has not been documented to mediate apoptotic cell death (Obeid et al, 1993). Intracellular ceramide was also increased directly by incubating cultures with $300 \mathrm{mU} / \mathrm{ml}$ sphingomyelinase (Staphylococcus aureus; Sigma). Glucosylceramide synthase was inhibited by exposing cells to PDMP ( $d$,l-threo-1-phenyl-2-decanoylamino-3-morpholino-1-propanol), a potent and competitive inhibitor of the enzyme (Matreya) (Li and Ladisch, 1997). The inactive diastereomer d,I-erythro-PDMP was used for comparison studies.

\section{Cholera toxin- $\beta$ staining}

Dissociated DRG cultures were exposed to $300 \mu \mathrm{M}$ suramin for $12 \mathrm{~h}$ to 4 days. Cultures were fixed in $4 \%$ paraformaldehyde followed by incubation with cholera toxin- $\beta$ subunit horseradish peroxidase conjugate, a specific marker for the monosialoganglioside $\mathrm{GM}_{1}$ (Research Biochemicals International, Natick, MA). Positive staining was detected by the chromagen diaminobenzidine. Parallel suramin treated cultures were exposed to the lysosomal marker, Texas Reddextran (Molecular Probes, Eugene, OR) overnight. Inclusion bodies/ lysosomes were observed in live cells under light and fluorescence microscopy (568 $\mathrm{nm}$ excitation wavelength).

\section{Electron microscopy}

DRG cultures exposed to $300 \mu \mathrm{M}$ suramin for various times were fixed in situ with Trump's fixative followed by $1 \mathrm{~h}$ postfixation in $1 \% \mathrm{OsO}_{4}$. Cultures were stained en bloc with $2 \%$ uranyl acetate, dehydrated and embedded in Spurr's resin. Sections $(0.8 \mu \mathrm{m})$ were examined with a Philips CM10 transmission electron microscope.

\section{Bis-benzimide staining}

Nuclear fragmentation and condensation were examined with bisbenzimide (Hoechst 33258; Sigma) staining. Following treatment, cultures were washed twice with phosphate buffered saline and fixed for a minimum of $1 \mathrm{~h}$ in methanol:acetic acid $(3: 1)$. Cultures were again washed in phosphate buffered saline and mounted with a drop of $50 \%$ glycerol $/ 50 \% \quad 0.1 \mathrm{M}$ Tris $-\mathrm{HCl}(\mathrm{pH} 7.4)$ containing $1 \mu \mathrm{g} / \mathrm{ml}$ bisbenzimide. Cultures were stored in the dark for a minimum of $15 \mathrm{~min}$ and then observed under a fluorescent microscope using Hoechst optics.

\section{DNA fragmentation}

DNA from enriched DRG neuronal cultures was prepared by modification of a previous method (Batistatou and Greene, 1993). After treatment, cells were washed in phosphate buffered saline and pelleted. Cells were lysed in $200 \mu$ of $50 \mathrm{mM}$ Tris-HCl pH 9.0, $20 \mathrm{mM}$ EDTA, $10 \mathrm{mM} \mathrm{NaCl}, 1.1 \%$ sodium dodecyl sulfate $(\mathrm{w} / \mathrm{v})$, and $10 \mathrm{mg} / \mathrm{ml}$ Proteinase $\mathrm{K}$ (GIBCO). Cells were incubated in lysis buffer for $48 \mathrm{~h}$ at $48^{\circ} \mathrm{C}$. Samples were cooled at room temperature for $15 \mathrm{~min}$ and sedimented. Two hundered microliters of phenol chloroform was added to each pellet, vortexed, and sedimented again. Following a second phenol chloroform extraction, an aliquot containing $5 \mu \mathrm{g}$ DNA was added to $50 \mu \mathrm{g} / \mu \mathrm{l}$ RNase A plus $3 \mu \mathrm{l}$ gel loading buffer and incubated at room temperature for $1 \mathrm{~h}$. Samples were electrophoresed in a $1.2 \%$ agarose gel and visualized with ethidium bromide.

\section{Ceramide measurement}

A modification of the method by Preiss and colleagues (Preiss et al, 1987) in which diacylglycerol kinase converts ceramide to ceramide-1$\left.{ }^{32} \mathrm{P}\right]$ phosphate was used. Briefly, lyophilized whole cell lysates of 
enriched DRG neuronal cultures were solubilized in $20 \mu \mathrm{l}$ of $7.5 \% \mathrm{n}$ octyl- $\beta$-D-glucopyranoside, $5 \mathrm{mM}$ cardiolipin, and $1 \mathrm{mM}$ diethelenetriaminepentaacetic acid solution by heating to $70^{\circ} \mathrm{C}$, followed by sonication and vortex-mixing. The volume was then brought to $100 \mu \mathrm{l}$ in a mixture containing $72 \mathrm{mM}$ imidazole, $12.5 \mathrm{mM} \mathrm{MgCl}_{2}, 2 \mathrm{mM}$ dithiothreitol, $1 \mathrm{mM}$ EDTA, $0.4 \mathrm{mM}$ diethylenetriaminepentaacetic acid, $50 \mathrm{mM} \mathrm{LiCl}, 50 \mu \mathrm{g} / \mathrm{ml}$ of diacylglycerol kinase and $1 \mathrm{mM}$ $\left[{ }^{32} \mathrm{P}\right]$ ATP $(5 \mu \mathrm{Ci})$. After $30 \mathrm{~min}$ at room temperature, phosphorylated lipids were extracted. Samples were spotted on high performance thin layer chromatography plates and developed in chloroform/methanol/ acetic acid ( $65: 15: 5$ by volume). Standards of ceramide-1-phosphate were used for identification of bands. The high performance thin layer chromatography plate was exposed to film and intensity of bands measured by optical densitometry.

Ceramide levels in suramin treated cultures were also measured by mass spectrometry (MS) as described previously (Gu et al, 1997; Watts et al, 1997). Neuron enriched DRG cultures were spun down and resuspended and sonicated in $1 \mathrm{ml}$ of $\mathrm{CH}_{3} \mathrm{OH} / \mathrm{H}_{2} \mathrm{O} / 12 \mathrm{M} \mathrm{HC}$ $(95: 5: 0.5 ; \mathrm{vol} / \mathrm{vol})$, and $0.6 \mathrm{ml}$ of ice-cold water was added. Lipids were prepared by partitioning them into $1 \mathrm{ml}$ of $\mathrm{CHCl}_{3}$, and the organic phases were recovered and dried in glass tubes. Two $\mathrm{ml}$ of $\mathrm{CHCl}_{3}$ were added with polar lipids removed by small-scale silica gel chromatography, and a single fraction spanning the known elution positions for ceramides varying from $\mathrm{C} 2: 0$ to $\mathrm{C} 24: 1$ was collected and dried. Lipids were resuspended in $5 \mathrm{mM}$ ammonium acetate in methanol with $\mathrm{C} 2: 0$ ceramide (Matreya) added to $200 \mathrm{pM} / \mu \mathrm{l}$ as an internal standard. Samples $(10 \mu \mathrm{l})$ were then infused into a PE-Sciex 365 triple quadropole mass spectrometer (Sciex, Toronto, Canada) by a Perkin Elmer 200 Autosampler, with a flow rate of $5 \mu \mathrm{l} / \mathrm{min}$. Mass analysis was performed as described previously (Watts et al, 1997).

\section{Acknowledgements}

The excellent secretarial assistance of Ms. Linda A. Goldbeck is greatly appreciated. Technical assistance was also provided by the Mayo Electron Microscopy Core Facility. We are grateful to Drs. Andrew Tomlinson and Brian Williamson, Mayo Mass Spectrometry Core Facility, for performing the mass spectrometry analysis of ceramide levels. Drs. Richard E. Pagano and Scott H. Kaufmann were extremely helpful in providing technical and intellectual support.

\section{References}

Akanji MA (1988) Rat kidney lysosomal membrane damage induced by suramin in vitro and in vivo. Pharmacol. Toxicol. 62: $318-321$

Batistatou A and Greene LA (1993) Internucleosomal DNA cleavage and neurona cell survival/death. J. Cell Biol. 122: 523-532

Betsholtz C, Johnsson A, Heldin C-H and Westermark B (1986) Efficient reversion of simian sarcoma virus-transformation and inhibition of growth factor-induced mitogenesis by suramin. Proc. Natl. Acad. Sci. USA 83: 6440-6444

Bielawska A, Crane HM, Liotta D, Obeid LM and Hannun YA (1993) Selectivity of ceramide-mediated biology. Lack of activity of erythro-dihydroceramide. J. Biol. Chem. 268: 26226-26232

Bornstein MB (1958) Reconstituted rat-tail collagen used as substrate for tissue cultures on coverslips in Maximow slides and roller tubes. Lab. Invest. 7: 134137

Broder S, Collins JM, Markham PD, Redfield RR, Hoth DF, Groopman JE, Gallo RC, Yarchoan R, Lane HC, Klecker RW, Mitsuya H, Gelmann E, Resnick L, Myers CE and Fauci AS (1985) Effects of suramin on HTLV-III/ LAV infection presenting as Kaposi's sarcoma or AIDS-related complex: clinical pharmacology and suppression of virus replication in vivo. Lancet 2 : $627-630$
Brugg B, Michel PP, Agid Y and Ruberg M (1996) Ceramide induces apoptosis in cultured mesencephalic neurons. J. Neurochem. 66: 733-739

Buys CHCM, Bouma JMW, Gruber M and Wisse E (1978) Induction of lysosomal storage by suramin. Naunyn-Schmiedeberg's Arch. Pharmacol 304: $183-190$

Cardinali M, Sartor O and Robbins KC (1992) Suramin, an experimental chemotherapeutic drug, activates the receptor for epidermal growth factor and promotes growth of certain malignant cells. J. Clin. Invest. 89: 12421247

Coffey RJ, Leof EB, Shipley GD and Moses HL (1987) Suramin inhibition of growth factor receptor binding and mitogenicity in AKR-2B cells. J. Cell. Physiol. 132: $143-148$

Constantopoulos G, Rees S, Cragg BG, Barranger JA and Brady RO (1981) Effect of suramin on the activities of degradative enzymes of sphingolipids in rats. Res. Commun. Chem. Pathol. Pharmacol. 32: 87-97

Deckwerth TL and Johnson EM, Jr (1993) Temporal analysis of events associated with programmed cell death (apoptosis) of sympathetic neurons deprived of nerve growth factor. J. Cell Biol. 123: 1207-1222

Edwards SN and Tolkovsky AM (1994) Characterization of apoptosis in cultured rat sympathetic neurons after nerve growth factor withdrawal. J. Cell Biol. 124:537546

Gansler T, Vaghmar N, Olson JJ and Graham SD (1992) Suramin inhibits growth factor binding and proliferation by urothelial carcinoma cell cultures. J. Urol. 148: 910-914

Gill JS, Hobday KL and WindebankAJ (1995) Mechanism of suramin toxicity in stable myelinating dorsal root ganglion cultures. Exp. Neurol. 133: 113-124

Gill JS, Connolly DC, McManus MJ, Maihle NJ and Windebank AJ (1996) Suramin induces phosphorylation of the high-affinity nerve growth factor receptor in PC12 cells and dorsal root ganglion neurons. J. Neurochem. 66: 963-972

Gill JS and Windebank AJ (1997) Role of ceramide in suramin-induced cancer cell death. Cancer Lett. 119: 169-176

Gill JS and Windebank AJ (1998) Activation of the high affinity nerve growth factor receptor by two polyanionic chemotherapeutic agents: role in drug induced neurotoxicity. J. Neurooncol. (in press)

Gu M, Kerwin JL, Watts JD and Aebersold R (1997) Ceramide profiling of complex lipid mixtures by electrospray ionization mass spectrometry. Anal. Biochem. 244: $347-356$

Hannun YA and Linardic CM (1993) Sphingolipid breakdown products: antiproliferative and tumor-suppressor lipids. Biochim. Biophys. Acta 1154: $223-$ 236

Hannun YA and Obedi LM (1995) Ceramide: an intracellular signal for apoptosis. Trends Biochem. Sci. 20: 73-77

Hawking F (1978) Suramin: with special reference to onchocerciasis. Adv. Pharmacol. Chemother. 15: 289-322

Hosang M (1985) Suramin binds to platelet-derived growth factor and inhibits its biological activity. J. Cell. Biochem. 29: 265-273

Kim JH, Sherwood ER, Sutkowski DM, Lee C and Kozlowski JM (1991) Inhibition of prostatic tumor cell proliferation by suramin: alterations in TGF alphamediated autocrine growth regulation and cell cycle distribution. J. Urol. 146: $171-176$

LaRocca RV, Stein CA, Danesi R and Myers CE (1990a) Suramin, a novel antitumor compound. J. Steroid Biochem. Mol. Biol. 37: 893-898

LaRocca RV, Stein CA, Myers CE, Dalakas M and McAtee N (1989) Suramin induced acute polyneuropathy. Proc. Annu. Meet, Am. Soc. Clin. Oncol. 8: 71(Abstract)

LaRocca RV, Meer J, Gilliatt RW, Stein CA, Cassidy J, Myers CE and Dalakas MC (1990b) Suramin-induced polyneuropathy. Neurology 40: 954-960

LaRocca RV, Cooper MR, Uhrich M, Danesi R, Walther MM, Linehan WM and Myers CE (1991) Use of suramin in treatment of prostatic carcinoma refractory to conventional hormonal manipulation. Urol. Clin. North Am. 18: 123-129

Li R and Ladisch S (1997) Inhibition of endogenous ganglioside synthesis does not block neurite formation by retinoic acid-treated neuroblastoma cells. J. Biol. Chem. 272: 1349-1354

Mahoney CW, Azzi A and Huang K-P (1990) Effects of suramin, an anti-human immunodeficiency virus reverse transcriptase agent, on protein kinase $\mathrm{C}$. Differential activation and inhibition of protein kinase $\mathrm{C}$ isozymes. J. Biol. Chem. 265: $5424-5428$

Obeid LM, Linardic CM, Karolak LA and Hannun YA (1993) Programmed cell death induced by ceramide. Science 259: $1769-1771$ 
Piqueras B, Autran B, Debre P and Gorochov G (1996) Detection of apoptosis at the single-cell level by direct incorporation of fluorescein-dUTP in DNA strand breaks. Biotechniques 20: 634-640

Pittman RN, Wang S, DiBenedetto AJ and Mills JC (1993) A system for characterizing cellular and molecular events in programmed neuronal cell death. J. Neurosci. 13: $3669-3680$

Pollak M and Richard M (1990) Suramin blockade of insulinlike growth factor Istimulated proliferation of human osteosarcoma cells [published erratum appears in J Natl Cancer Inst 1990 Sept 19; 82: 1510]. J. Natl. Cancer Inst. 82: $1349-1352$

Preiss JE, Loomis CR, Bell RM and Niedel JE (1987) Quantitative measurement of sn-1,2-diacylglycerols. Methods Enzymol. 141: 294-300

Rees S (1978) Membranous neuronal and neuroglial inclusions produced by intracerebral injection of suramin. J. Neurol. Sci. 36: 97-109

Rees S, Constantopoulos G, Barranger JA and Brady RO (1982) Organomegaly and histopathology in an animal model of mucopolysaccharidosis induced by suramin. Naunyn Schmiedebergs Arch. Pharmacol. 319: 262-270

Russell JW and Windebank AJ (1993) Electrophysiological and pathological characteristics of suramin-induced neuropathy. Neurology 43: A174(Abstract)

Sartor O, McLellan CA, Myers CE and Borner MM (1992) Suramin rapidly alters cellular tyrosine phosphorylation in prostate cancer cell lines. J. Clin. Invest. 90: 2166-2174
Sjölund M and Thyberg J (1989) Suramin inhibits binding and degradation of plateletderived growth factor in arterial smooth muscle cells but does not interfere with autocrine stimulation of DNA synthesis. Cell Tissue Res. 256: 35-43

Stein CA, LaRocca RV, Thomas R, McAtee N and Myers CE (1988) Suramin: an active agent in metastatic adrenocortical carcinoma. Proc. Annu. Meet. Am. Soc. Clin. Oncol. 7: A345(Abstract)

Tsutsumi K, Kitagawa N, Niwa M, Yamaga S, Khalid H, Taniyama K, Himeno A and Shibata S (1993) Biphasic effects of suramin on ${ }^{125}$ I-epidermal growth factor binding to human meningiomas. Cell Mol. Neurobiol. 13: 665-675

Tsutsumi K, Kitagawa N, Niwa M, Himeno A, Taniyama Kand Shibata S (1994) Effect of suramin on ${ }^{125}$-insulin-like growth factor-I binding to human meningiomas and on proliferation of meningioma cells. J. Neurosurg. 80: 502-509

Watts JD, Gu M, Polverino AJ, Patterson SD and Aebersold R (1997) Fas-induced apoptosis of T cells occurs independently of ceramide generation. Proc. Natl. Acad. Sci. USA 94: 7292-7296

Wiesner D and Dawson G (1996) PCD in neuronal cells is dependent on the formation of ceramide. J. Neurochem. 66: S25(Abstract)

Wyllie AH, Kerr JF and Currie AR (1980) Cell death: the significance of apoptosis. Int Rev. Cytol. 68: 251-306

Wyllie AH (1985) The biology of cell death in tumours. Anticancer Res. 5: 131-136 